\title{
SUSTENTABILIDADE NO CONSUMO COLABORATIVO: UMA REFLEXÃO SOBRE A DISSEMINAÇÃO DE VALORES SUSTENTÁVEIS A PARTIR DE TROCADORES DE LIVROS
}

\section{SUSTANABILITY IN COLLABORATIVE CONSUMPTION: A REFLECTION ABOUT DISSEMINATION OF SUSTAINABLE VALUE FROM THE TRIBE OF BOOK EXCHANGERS}

\author{
Roberto Zimmer Araujo, Mestrando PPGDesign (UNISINOS) \\ Karine Freire, Dra. PPGDesign (UNISINOS) \\ Palavras Chave \\ Design; Sustentabilidade; Consumo Colaborativo
}

\section{Key Words}

Design; Sustainability; Collaborative Consumption

\section{Resumo}

Este artigo foi desenvolvido para analisar as formas de consumo colaborativo de trocadores de livros como um modo disseminação de valores para sustentabilidade, uma tribo com estrutura difusa cujo elo de ligação é a leitura por prazer. A partir de entrevistas em profundidade com membros desta tribo e da observação não participante de suas ações, foram investigadas características relevantes do processo de difusão de valores sustentáveis para que designers possam se apropriar e projetar sistemas colaborativos que contribuam com o desenvolvimento de uma cultura de sustentabilidade. Entre os elementos mais evidentes estão o valor da história e memória dos produtos, do coletivo e comunitário, do consumo com cuidado e conservação, e da experiência ampliada a novos sentidos para os objetos, que segundo Malaguti (2009) são alguns dos valores fundamentais para uma cultura de sustentabilidade.

\section{Abstract}

This paper was developed to analyze the ways of collaborative consumption of books exchangers as a means of spread values for sustainability, a tribe with diffuse structure and which linking value is reading for pleasure. From interviews with members of this tribe and non-participant observation of their actions, it was investigated relevant characteristics of the process of diffusion of sustainable values to designers be able to appropriate it and design collaborative systems which contribute with the development of a sustainable culture. Among the more evident elements are the value of history and memory of products, of collective and communitarian, of consume with care and conservation, and of the extended experience to new SENTIDOS to the objetcs, which to Malaguti (2009) are some of the values do a sustainable culture. 


\section{INTRODUÇÃO}

O consumo é um fenômeno que não se limita a escolha de um artefato em função do benefício primário que lhe é atribuído. $\mathrm{O}$ indivíduo se comunica com o ambiente social a partir de diversas formas, inclusive do consumo. E mais, a compra e o consumo de um determinado objeto podem ser considerados, pela visão de Featherstone (1995), como um meio de estabelecer relações sociais. Ou ainda, como uma forma de afirmação da identidade e integração a grupos sociais (BAUDRILLARD, 1995), o que pode se desdobrar na formação de tribos de consumo. A partir disso, sugere-se que o estabelecimento de tribos explora o processo de comunicação do indivíduo com o ambiente a partir do consumo e sua relação de pertencimento a grupos sociais. Esta expressão do indivíduo está articulada a dimensão simbólica dos artefatos e aos significados atribuídos a eles e ao processo de consumo.

Essa dimensão simbólica se relaciona ao valor social do consumo, que consiste em aspectos sociais que permeiam processos de produção, comercialização e consumo dos produtos, inclusive valores morais e a atuação e reputação das organizações (KRUCKEN; TRUSEN, 2009). Dessa forma, sugere-se que as relações sociais numa tribo de consumo são capazes de influenciar hábitos entre indivíduos em função do compartilhamento destes valores.

Considerando tribos de consumo colaborativo, considera-se a possibilidade de que o valor social dessa forma de consumo esteja relacionado à sustentabilidade, e por isso pode contribuir para a difusão de uma cultura de sustentabilidade entre seus integrantes. Segundo Botsman e Rogers (2011), os sistemas colaborativos surgem como um contraponto a lógica econômica dominante e buscam, a partir de redes sociais inteligentes suportadas por base tecnológica novas formas de consumo. No entanto, se observa que essas novas formas de consumo relacionam um diferente conjunto de elementos que passam a ser valorizados na ocasião do consumo, e que fortalecem a projeção de identidade.

Este artigo foi elaborado com o objetivo de identificar os modos pelos quais uma tribo de consumo colaborativo pode difundir os valores de sustentabilidade, e para isso explora as características da tribo de trocadores de livros. A tribo é constituída por consumidores em sistemas de redistribuição de livros, ou seja, portais virtuais que promovem relações horizontais entre leitores que disponibilizam livros e propõem trocas entre si.

\section{TRIBOS DE CONSUMO}

No ato de comprar e consumir, um indivíduo não busca apenas o valor concreto daquilo que consome, como se alimentar de algo para saciar sua fome ou comprar uma peça de roupa para se abrigar do frio, mas também um valor abstrato relacionado a um conceito que envolve características e qualidades que irão diferenciá-lo dos demais indivíduo, e pelo qual os indivíduos expressam para o mundo algo sobre si mesmos (FEATHERSTONE, 1995; DOUGLAS;ISHERWOOD, 2004)

Com base nisso, compreende-se que a cultura de consumo proporciona aos indivíduos uma maior expressão de sua personalidade a partir das escolhas de compra e consumo que efetua. A dimensão simbólica dos artefatos, portanto, dialoga com a possibilidade de expressão do indivíduo, o que contribui para que as escolhas de consumo sejam um modo de afirmação de identidade consigo e com os demais.

McCracken (2003) aponta que os bens de consumo nos quais o consumidor investe tempo, atenção e seus recursos financeiros, estão carregados de significados culturais, sendo estes significados utilizados pelos consumidores para expressão individual e de seus princípios, construção de noções de si, cultivo de ideais, criação e sustentação de estilos de vida. Essa identificação com grupos sociais pode acontecer na forma de tribos de consumo. Segundo Cova e Cova (2001), tribos são unidades de referência utilizadas em pesquisas pós-modernas sobre consumidores que consistem em grupos de indivíduos que compartilham experiências similares e emoções e se unem em comunidades vagamente interligadas. Estes são agrupamentos difusos de consumidores na sociedade contemporânea.

O estabelecimento destes grupos tem por característica a instabilidade ou efemeridade. Diferente de grupos de referência ou subculturas de consumo, não existe uma relação clara de hierarquia, autoridade, ethos e uma rígida estrutura na tribo. Para Cova e Cova (2001), as tribos são agregados dinâmicos de pessoas emocionalmente conectadas cuja relação é difusa e difícil de medir, pois muitas vezes não chegam a ser explícitas. A relação entre as pessoas numa tribo é sustentada pelo linking value, ou seja o elemento de ligação que mantém a identificação dos int egrantes do grupo. Tribos também são caracterizadas por traços temporais: num ciclo de vida mais curto elas emergem, crescem, atingem um pico, declinam e se desfazem.

Conforme indicam Douglas e Isherwood (2004), bens são acessórios rituais e o consumo é um processo ritual no qual a função primária é dar sentido a um fluxo de acontecimentos. Considerando esta indicação, se compreende que ao praticar um ritual de consumo, e não somente o consumo por si, o indivíduo passa a comunicar ao meio social a reafirmação de sua noção de si e identificação com a tribo. 


\section{CONSUMO COLABORATIVO COMO UMA ALTERNATIVA PARA SUSTENTABILIDADE}

A partir da década de 1970, Lipovetsky (2007) destaca a presença de maior individualismo e consumismo na sociedade contemporânea, e passa a defini-la como "sociedade de hiperconsumo". A sociedade do hiperconsumo é caracterizada por ações de capitalismo predatório que se forma em um ambiente em que a produção em série e larga escala, sistema que passa a ser questionado como a melhor opção para o consumidor. Percebe-se uma desaceleração do consumo em função de uma possível saturação do mercado de massa. Essa saturação introduz ao consumidor aos poucos uma nova esfera de questionamentos e avaliação de questões ligadas a culpa, consciência social e bem-estar social. O consumidor, aos poucos, passa a procurar alternativas que reduzem o impacto social e ambiental de seu consumo, principalmente no que se refere a desigualdade entre classes sociais e a escassez de recursos naturais. (LIPOVETSKY, 2007).

Neste contexto, o sistema econômico contemporâneo passa a ser composto também por organizações que exploram outras formas de consumo, estimulando diferentes formas de interesse do consumidor e promovendo variedade no mercado de massa. (LIPOVETSKY, 2007). Como uma dinâmica alternativa, se observa na sociedade contemporânea movimentos que promovem o consumo colaborativo. Segundo Botsman e Rogers (2011), o compartilhamento é a base de um sistema cultural e econômico emergente que inspira diferentes modelos de negócio. Os negócios que se constituem na lógica do consumo colaborativo estruturam uma rede entre usuários que promove compartiIhamento, troca, empréstimo, microaluguel, empréstimo e doações de bens através de tecnologia. Independente da sua motivação principal, o consumidor que decide consumir colaborativamente está buscando uma solução prática, seja ela a economia de tempo ou de recursos financeiros, o acesso a um serviço que atende melhor suas necessidades, ser mais sustentável ou permitir relacionamentos mais estreitos com pessoas e não com marcas. (BOTSMAN; ROGERS, 2011). Pode-se dizer que o consumo colaborativo é um modo de consumo consciente, na perspectiva do Instituto Akatu (2002, p.9): "ser um consumidor consciente significa fazer de seu ato de compra um ato de cidadania, isto é, ser capaz de escolher produtos, serviços e empresas fornecedoras que contribuam para uma condição de vida ambientalmente sustentável e socialmente justa.

O consumo colaborativo também está relacionado a ideia de consumo suficiente apresentada por Alcott (2008), em especial a primeira de suas duas premissas, que é uma forma de consumo que estimula a consciência da sustentabilidade. A primeira premissa do consumo suficiente afirma que o consumidor está apto a consumo, ou seja, o consumo é uma escolha e não uma condição. Ou seja, o consumidor colaborativo está apto às formas tradicionais de consumo, mas opta por esta alternativa.

A segunda premissa do consumo suficiente diz respeito à motivação para consumo. Alcott (2008) coloca que o consumo é limitado por diversos aspectos, e o ponto que motiva o menor consumo no seu conceito de suficiência é relacionado ao impacto ambiental. Este artigo chama atenção também a relevância de considerar além do impacto ambiental, o impacto social do consumo.

Por considerar estes impactos, compreende-se que o consumo colaborativo é um fenômeno capaz de disseminar valores para uma cultura de sustentabilidade a partir do estímulo a consciência em relação ao consumo. Malaguti (2009) contribui com esta questão ao sugerir uma série de valores relacionados a sustentabilidade para transformação de uma cultura de hiperconsumo para uma cultura sustentável, relacionados na tabela 1. Os valores para uma cultura sustentável refletem consciência em relação ao impacto do consumo, o que se articula a ideia de consumo consciente de Akatu (2002) e suficiente de Alcott (2008).

Para Malaguti (2009), os valores fundamentais para construção de uma cultura de sustentabilidade apresentam diferentes possibilidades de desdobramento em processos de projeto. Ao serem projetados considerando estes valores, produtos e serviços os carregam intrinsicamente e compõe a comunicação do indivíduo com o meio social através do consumo, bem como passam a ser compartilhados com os demais em grupos sociais como as tribos de consumo.

Manzini e Vezzoli (2005) colocam que é papel do design para sustentabilidade articular o que é tecnicamente possível com o que é ecologicamente necessário. Com isso, um caminho do design para sustentabilidade é seguir na sugestão de Alcott (2008) de articular tecnologias sociais de modo que gerem consciência em relação ao impacto do consumo por meio da fronteira entre necessidade e desejo e o senso inato de justiça, sendo que a articulação destes elementos da forma ecologicamente necessária, sendo Manzini e Vezzoli (2005), é papel do design para sustentabilidade.

Manzini e Vezzoli (2005) também colocam que "desenvolver atividades no plano cultural que tendam a promover novos critérios de qualidade" é uma maneira de contribuição do design para sustentabilidade. O consumo colaborativo é um fenômeno que permite reflexão em relação ao consumo e a articulação com a construção para cultura de sustentabilidade a partir da disseminação 
Tabela 1: Valores associados a consumo e sustentabilidade.

\begin{tabular}{|l|l|}
\hline Valores relacionados a consumo & Valores relacionados a sustentabilidade \\
\hline $\begin{array}{l}\text { Consumo no sentido predatório (destrutivo, } \\
\text { que devora e gasta até o fim dos recursos). }\end{array}$ & Cuidado, conservação, fruição. \\
\hline $\begin{array}{l}\text { Acúmulo de coleções e experiências superfi- } \\
\text { ciais. }\end{array}$ & $\begin{array}{l}\text { Ampliação da experiência com novos sen- } \\
\text { tidos e usos para objetos. }\end{array}$ \\
\hline $\begin{array}{l}\text { Conveniência associada ao hábito do descar- } \\
\text { te. }\end{array}$ & $\begin{array}{l}\text { Outras “conveniências", como sobrevivên- } \\
\text { cia, manutenção, equilíbrio. }\end{array}$ \\
\hline Virgindade, novo, eterna juventude. & $\begin{array}{l}\text { Velhice, história, memória, experiência e } \\
\text { marcas acumuladas com o tempo, durabi- } \\
\text { lidade. }\end{array}$ \\
\hline $\begin{array}{l}\text { Compreensão de luxo como ostentação, } \\
\text { aparência, exclusividade, ousadia ou trans- } \\
\text { gressão gratuita. }\end{array}$ & $\begin{array}{l}\text { Compreensão do luxo como atitude com- } \\
\text { prometida com uma causa, coragem para } \\
\text { rupturas e qualidade de vida. }\end{array}$ \\
\hline $\begin{array}{l}\text { Criação de ídolos como referenciais de iden- } \\
\text { tidade e beleza. }\end{array}$ & $\begin{array}{l}\text { Conceito amplo de beleza que respeita e } \\
\text { valoriza a diversidade. }\end{array}$ \\
\hline Propriedade e posse individual. & $\begin{array}{l}\text { Valorização do bem-comum, do coletivo, } \\
\text { do comunitário. }\end{array}$ \\
\hline
\end{tabular}

Fonte: Malaguti (2009), com adaptações.

de seus valores fundamentais. Para o design sustentável é pertinente exploradas as características dos grupos sociais que praticam este consumo colaborativo e como a disseminação destes valores acontece.

As tecnologias sociais, e neste contexto sugere-se as redes formadas entre consumidores para o exercício da troca de livros das diversas formas como podem se estabelecer, presentes nos negócios que promovem consumo colaborativo permitem relacionamentos mais estreitos com pessoas e não com marcas sugere a possibilidade de uma relação mais pessoal entre consumidores, os sensibilizando em relação a uma constituição de tribos de consumo. Belk (2010) afirma que nos sistemas colaborativos é estabelecida uma ligação social entre envolvidos, o que não indica necessariamente a constituição de uma tribo de consumo, bem como não a nega, mas inspira a reflexão a respeito da relação deste consumo com afirmação da sua identidade e reconhecimento com um grupo.

Para Botsman e Rogers (2011), consumo colaborativo está relacionado ao ressurgimento de um senso de comunidade na sociedade, que diz respeito a um maior interesse das pessoas em participar ativamente dos processos que envolvem aquilo que compram e consomem, ou seja, assumir uma postura menos passiva em relação a seu lugar na cultura de consumo. Com isso, o sistema colaborativo pode ser percebido como uma área fértil para a criação de tribos de consumo uma vez que estimula a participação do consumidor nos processos envolvidos àquilo que consome, ampliando sua relação com os diversos signos ali representados e a possibilidade de identificação, bem como uma também maior relação entre indivíduos no sistema, o que pode contribuir para a identificação do usuário com o coletivo.

É pertinente observar que esta visão está estreitamente relacionada a valorização do bem comum, do coletivo e do comunitário ao invés do individual, o que é colocado por Malaguti (2009) como um dos valores fundamentais da cultura de sustentabilidade. Sendo o sistema colaborativo uma alternativa emergente frente ao contexto social de hiperconsumo (BOTSMAN; ROGERS, 2011), é possível que os usuários sejam caracterizados pela crítica em relação a fatores do sistema vigente. No processo de comunicação com o meio social que um usuário produz ao consumir colaborativamente, o indivíduo reforça sua identificação como pertencente a uma tribo que questiona a situação vigente e que se empenha nas soluções emergentes. No sentido de ampliar o debate sobre esta colocação, a próxima seção é dedicada a explorar características de uma tribo de consumo colaborativo.

\section{METODOLOGIA}

Para compreender as formas de colaboração para disseminação de valores sustentáveis por trocadores de livros, foi realizada uma pesquisa qualitativa exploratória, 
Tabela 2: Trocadores de livros entrevistados

\begin{tabular}{|l|l|l|l|l|}
\hline Identificação & Profissão & $\begin{array}{l}\text { Local de residên- } \\
\text { cia }\end{array}$ & $\begin{array}{l}\text { Portais de tro- } \\
\text { ca de livro que } \\
\text { utiliza }\end{array}$ & $\begin{array}{l}\text { Meio de realiza- } \\
\text { ção da entrevista }\end{array}$ \\
\hline Entrevistado A & Designer & São Paulo/SP & Trocando Livros & $\begin{array}{l}\text { Ligação telefô- } \\
\text { nica }\end{array}$ \\
\hline Entrevistado B & $\begin{array}{l}\text { Autônomo (ser- } \\
\text { viços industriais })\end{array}$ & São Paulo/SP & Trocando Livros & $\begin{array}{l}\text { Conversação } \\
\text { instantânea por } \\
\text { escrito }\end{array}$ \\
\hline Entrevistado C & Nutricionista & Varginha/MG & $\begin{array}{l}\text { Skoob; Trocando } \\
\text { Livros }\end{array}$ & $\begin{array}{l}\text { Chamada de voz } \\
\text { via internet }\end{array}$ \\
\hline Entrevistado D & Industriário & $\begin{array}{l}\text { São Sebastião do } \\
\text { Caí/RS }\end{array}$ & $\begin{array}{l}\text { Skoob; Trocan- } \\
\text { do Livros; Livra } \\
\text { Livro }\end{array}$ & $\begin{array}{l}\text { Conversação } \\
\text { instantânea por } \\
\text { escrito }\end{array}$ \\
\hline Entrevistado E & $\begin{array}{l}\text { Consultor de } \\
\text { Tecnologia da } \\
\text { Informação }\end{array}$ & $\begin{array}{l}\text { Três Corações/ } \\
\text { MG }\end{array}$ & $\begin{array}{l}\text { Skoob; Livra } \\
\text { Livro }\end{array}$ & $\begin{array}{l}\text { Conversação } \\
\text { instantânea por } \\
\text { escrito }\end{array}$ \\
\hline Entrevistado F & $\begin{array}{l}\text { Estudante de } \\
\text { Arquitetura e } \\
\text { Urbanismo }\end{array}$ & São Paulo/SP & $\begin{array}{l}\text { Trocando Li- } \\
\text { vros; Livra Livro; } \\
\text { Book Smooch }\end{array}$ & $\begin{array}{l}\text { Conversação } \\
\text { instantânea por } \\
\text { escrito }\end{array}$ \\
\hline
\end{tabular}

Fonte: Elaborado pelos autores (2016).

com pesquisas bibliográficas, documentais e de campo. A partir da definição do campo como os portais de trocas de livros, foram realizadas seis entrevistas em profundidade com trocadores de livros, que já haviam efetuado no mínimo uma operação de troca. Os trocadores de livros foram identificados dentro das comunidades de troca, contatados via por mensagens dentro destes portais e convidados a entrevista, podendo ser realizada da forma que melhor Ihe conviesse - via chamada de vídeo, de áudio ou mensagens pela internet, ou telefônica. Na tabela 2 estão relacionadas informações sobre os trocadores de livro entrevistados. As entrevistas foram realizadas em setembro de 2012.

Além das entrevistas, foi realizada observação não participante das interações dos seis trocadores de livros no ambiente digital por dois meses (setembro e outubro de 2012) com outros usuários a partir dos espaços de diálogo abertos nos portais.

\section{TRIBO DOS TROCADORES DE LIVROS E DISSEMINAÇÃO DE VALORES SUSTENTÁVEIS}

Existem diversas formas de sistemas que reproduzem a lógica do consumo colaborativo. Entre as mais conhecidas, estão aquelas que adaptam às novas tecnologias antigos hábitos de escambo. Este é o princípio norteador do "mercado de redistribuição", um sistema que baseia-se na troca de produtos físicos obsoletos entre indivíduos, partindo do princípio de que o bem não tem mais serventia para o atual dono, mas pode ter para um novo. Estes sistemas existem em formato de trocas livres entre usuários e também em plataformas de revenda. (BOTSMAN; ROGERS, 2011)

No mercado de redistribuição do Brasil, um produto bastante presente é o livro. Além de haver um grande número de portais exclusivos de redistribuição de livros, em portais de redistribuição não especializados é comum a presença deste de produto ou até seções específicas. Nos portais de redistribuição de livros, sejam portais especializados neste produto ou generalistas que contenham esta oferta, os usuários se conectam entre si para promoção de trocas. Este artigo não faz distinção entre portais especializados ou generalistas que disponibilizam este tipo de item.

Chama atenção nas comunidades de troca, em primeiro momento, a relação que se estabelece entre os usuários. Entre os usuários observados, identificou-se que eles mantém um breve relacionamento durante a combinação da troca que vai além da negociação formal, se estendendo a gostos semelhantes entre indivíduos e situação de identificação entre pares.

É interessante apontar que os trocadores de livros pesquisados apresentam o hábito de se comunicar de forma tecnomediada. Os seis usuários observados mantêm perfis 
em redes sociais diversas, sendo que parte deles mantém fóruns e grupos variados dedicados a leitura por lazer nestas redes. Este fator indica o hábito dos consumidores destes serviços em trocar de informação referente à literatura. Esta relação com a informação de literatura por lazer se constitui como o linking value de uma tribo de consumidores formada por trocadores de livros. A relação que se desenvolve entre os consumidores é entre leitores, e por isso existe uma identificação entre estas pessoas pela partilha do gosto em comum, como pode ser percebido na afirmação do Entrevistado C: "a principal característica das pessoas envolvidas neste processo é a própria colaboração e compartilhamento dos mesmos interesses".

Os interesses compartilhados pelos consumidores são compreendidos como a marca que demonstra um conjunto de valores para o usuário, o que dialoga com a perspectiva de Belk (2010), na qual é marcante no processo colaborativo a imaterialidade do produto, ou seja, o conjunto de valores que se aplicam a ele e não o produto propriamente dito: mesmo que o resultado final da operação seja o livro, o processo de consumo envolve um conjunto de valores que supera a instância física. Este elemento fica evidente na afirmação do Entrevistado $A$ ao comentar que "o livro não é apenas um objeto, ele tem uma história".

Esta dimensão está relacionada ao valor para sustentabilidade colocado por Malaguti (2009) referente a história, velhice, memória, experiência e marcas acumuladas com o tempo, em detrimento da valorização da virgindade, do novo e da eterna juventude. Valorizar a dimensão histórica de um livro trocado é evidência da disseminação de um valor fundamental da sustentabilidade pela tribo de trocadores de livros. O Entrevistado A também afirma que "pode encontrar no site (portal de troca de livros) preciosidades, raridades, (...) uma preciosidade que é importante para você, mas que para outra pessoa não tem mais valor", o que torna ainda mais evidente a valorização da história e da memória por meio dos acervos dos usuários ao invés da evidência aos lançamentos e novos livros atribuída pelo comércio literário tradicional.

Entre trocadores de livros se percebe afeição, mesmo sem que se conheçam de fato. As operações no mercado de redistribuição de livros ocorrem pela internet em todo território brasileiro, no entanto, ao estabelecerem uma conexão de troca, os usuários estabelecem uma relação de afeto, como pode ser percebido no relato do Entrevistado A, a seguir:

"Quando você faz a compra tradicional, você faz a troca direta com um ser que não existe chamado livraria. Eu não me preocupo se a Cultura (livraria) vai ficar triste comigo, mas eu realmente me preocupo se aquelas pessoas que me pediram o livro (no sistema de troca) vão ficar tristes se o livro não chegar direito na casa delas ou se eu recusar. Por que recusar uma troca? Corta o coração recusar uma troca. Já se a Cultura me disser que o livro que eu quero não tem disponível eu não vou ficar triste com ela. Quando você está dentro da comunidade (de trocas) existe uma parte afetiva envolvida e a grande maioria das pessoas não quer desapontar a outra pessoa". (Entrevistado A)

Fatores como estes expressam o valor fundamental para sustentabilidade de Malaguti (2009) de ampliação da experiência ao invés de experiências superficiais na cultura de hiperconsumo. No lugar da experiência superficial da aquisição de um livro a partir do comércio tradicional, o trocador de livro tem essa experiência ampliada num contexto ao interagir com outros consumidores e explorar sentimentos humanos como afeição entre estes usuários.

Essa experiência ampliada estimula também o cuidado, a conservação e a fruição ao invés do consumo no sentido destrutivo, que representa outro valor para sustentabilidade proposto por Malaguti (2009). No contexto colaborativo o livro é um produto que deve ser consumido com cuidado e conservado uma vez que será trocado com outros consumidores também. A afeição que se estabelece entre trocadores pela experiência ampliada pode estimulá-los a conservação do livro no melhor estado físico possível para que os próximos consumidores que o possuírem tenham com ele também uma experiência agradável.

É interessante pontuar que foi observado estreitamento temporário no relacionamento entre indivíduos, um fato recorrente durante as trocas. Foi percebido que no momento em que dois usuários iniciam uma negociação de troca, é comum eles adicionarem seus perfis na rede de troca e permanecerem algum tempo conversando a respeito dos livros trocados ou outros. Em alguns casos, os usuários migram essa amizade para outras plataformas digitais de interação e redes sociais diversas, bem como ambientes presenciais, a exemplo do encontro de Skoobers (usuários da rede social Skoob, específica para leitores e que proporciona ambiente de trocas) do Rio Grande do Sul, evento periódico no qual usuários se reúnem em determinado local de Porto Alegre para conversar sobre literatura.

Embora esta relação emocional esteja estabelecida e seja facilmente percebida, ela é difusa e de difícil medição, o que se articula às características de uma tribo de consumo de acordo com Cova a Cova (2001). A relação emocional se articula também a um sentimento de comunidade 
que constitui um ambiente de solidariedade e acolhimento. Este fator reforça os valores para sustentabilidade de cuidado e conservação do produto articulado a experiência ampliada no contexto colaborativo, bem como a valorização do bem comum e do coletivo (MALAGUTI, 2009).

Os trocadores de livro também comentam sobre fatores relacionados a entretenimento no uso destes sistemas. O Entrevistado E destaca: "o valor econômico contribui bastante para a troca de livros, mas também uso por ser divertido". Na fala se compreende a associação o benefício econômico, fortemente presente no sistema de redistribuição, com uma prática agradável, somando benefícios. É pertinente observar a menção do fator econômico pelo Entrevistado $E$, que é frequentemente comentado entre os entrevistados, como o Entrevistado B que ao comentar "trocando se economiza, pois quando existe a troca não é necessário pagar o preço de um novo produto" traz com clareza o benefício econômico percebido na troca. É interessante refletir sobre este ponto não só por ser um benefício bastante pontuado pelos usuários e por isso compreendido como altamente relevante, mas também por articular a ideia da vantagem econômica a um ambiente afetivo e relacionado ao lazer do consumidor. A identificação dessa vantagem também reforça o estímulo para maior cuidado, conservação e fruição dos livros, disseminando este valor para sustentabilidade.

É interessante observar que a aliança do benefício econômico fortemente presente e do sentimento de comunidade estimula um maior volume de consumo. Em função de a aquisição de livros pelos trocadores envolver menor custo financeiro (apenas a despesa de transporte) e da capitalização da capacidade ociosa dos livros já lidos, é relatado como um hábito haver uma frequência maior de trocas do que se praticava de compras tradicionais antes da adesão à rede, como pode ser percebido no relato do Entrevistado $\mathrm{E}$.

"A frequência de troca é maior do que a de compra. Até não costumava comprar muito antes, mas a partir do momento em que conheci os sites de troca aumentou meu hábito também de comprar em sebos para ter maior volume de livros e poder estar trocando". (Entrevistado E)

É pertinente observar que o conceito expandido do livro adquirido no sistema de troca é basicamente restrito ao trocador. O usuário do sistema de troca de livro compreende a dimensão simbólica comentada e a valoriza em processos individuais, no entanto, existe uma diferença quando o livro em questão não é para sua propriedade. Entre os trocadores de livros entrevistados houve uma rejeição inicial em relação a possibilidade de uso de livros adquiridos em sistemas de troca para presentear pessoas de fora da tribo. Alguns usuários comentaram que já haviam presenteado amigos e familiares com livros adquiridos em sistemas de redistribuição, mas como presentes casuais ou informais, fora de datas festivas. Para tais eventos, ainda há preferência pela alternativa de um livro novo ou então presentear com um livro usado somado a outro presente. Estes fatores podem ser percebidos no relato do Entrevistado C, a seguir, que os articula mais a disseminação de valores para cultura de sustentabilidade de cuidado, conservação e fruição segundo Malaguti (2009).

"Para presentear alguém dependeria do estado de conservação do livro. Se fosse um livro que eu sei que a pessoa quer muito, não tem problema. Ou então um livro que estivesse muito bem conservado, mas aí só podemos ter certeza depois de receber o livro (após a troca). (...) Já utilizei livros trocados para presentear meus pais, por exemplo, mas era data especial, então também tinha comprado outras coisas para dar junto". (Entrevistado C)

No processo de comunicação com o ambiente social a partir do consumo (FEATHERSTONE,1995), quando o trocador de livro adquire um livro trocado para si comunica a importância que dá a imaterialidade do produto sugerida por Belk (2010), que neste produto relaciona a história do objeto, a valorização de seus recursos financeiros e o compartilhamento com um grupo de indivíduos com gostos semelhantes. No entanto, na situação da entrega de um presente, esta dimensão imaterial se fragiliza, e possivelmente em função de outros valores que tenha intensão de comunicar, o sistema não atende as expectativas. A relação que os entrevistados fazem com o presente numa data especial sugere que o fato de o livro trocado ter um valor menor em moeda possa ser uma evidência de depreciação da importância do presente, e por isso a preferência pelo artefato novo.

Um elemento que compõe a proposta de valor do mercado de redistribuição de livros é a respeito da sustentabilidade ambiental promovida através da reutilização de bens. Esta sustentabilidade existe uma vez que é diminuído o número de objetos a serem descartados e a geração de resíduos (BOTSMAN; ROGERS, 2011). É interessante refletir sobre a relação entre a tribo de trocadores de livros e o pensamento ecológico. Se percebe que estes consumidores pontuam este como um benefício da sua prática, no entanto colocam isso como um benefício lateral. Os consumidores se identificam com esta característica, mas não se compreende que ela seja determinante para participação no sistema. 
Em relação a isso, Botsman e Rogers (2011) afirmam que a evidência de ações ambientalmente corretas neste sistema é decorrente de processos que não exijam esforços extras. O consumo colaborativo se coloca originalmente como um contraponto a uma sociedade de hiperconsumo (LIPOVETSKY, 2007) que apresenta como uma consequência o hábito do descarte e a geração excessiva de resíduos. O ativismo ecológico, portanto, é um dos pilares que fundamentam o sistema, no entanto tem um significado explícito de menor relevância entre os trocadores de livros entrevistados, sendo evidente implicitamente no sistema colaborativo que se estabelece.

\section{CONSIDERAÇÕES FINAIS}

A partir da revisão proposta, se pode compreender os trocadores de livros como uma tribo de consumo na perspectiva de perspectiva de Cova e Cova (2001), que estabelece um aglomerado de pessoas emocionalmente conectadas cuja relação é difusa e difícil de medir, sendo que em determinados momentos a relação entre indivíduos não é explícita. A relação entre os indivíduos dessa tribo é sustentada pelo linking value, ou elemento de ligação, da literatura por lazer, e entre eles se estabelece uma relação afetiva. É importante pontuar que não há hierarquia ou estruturas demarcadas neste conjunto de pessoas, bem como não há um ethos ou fronteiras estabelecidas, o que seriam elementos necessários para caracterização deste grupo de consumidores como uma expressão de grupo melhor estruturada, assim como subculturas de consumo.

A partir da análise das características da tribo de trocadores de livros pode-se compreender que o fenômeno do consumo colaborativo é capaz de disseminar valores para uma cultura de sustentabilidade já que explora uma consciência em relação aos impactos sociais e ambientais do ato de consumir. Entre os valores fundamentais para uma cultura de sustentabilidade para Malaguti (2009) os mais evidentes no contexto estudado foram: (1) o valor da história, velhice e memória do produto ao invés da virgindade, do novo e da eterna juventude; (2) o valor do bem comum, do coletivo e comunitário no lugar da propriedade individual; (3) cuidado, conservação e fruição no lugar do consumo de modo destrutivo; e (4) ampliação da experiência com os sentidos ao invés de experiências superficiais. Estas características estão relacionadas a dimensão imaterial do produto, aspecto pontuado por Belk (2010) como relevante em processos de compartilhamento.

Estes valores para sustentabilidade estão intrínse$\cos$ no sistema colaborativo e se disseminam entre os consumidores. É interessante observar que os trocadores de livros pesquisados por vezes não compreendem o consumo colaborativo que praticam como uma ação sustentável, embora concordem com o princípio. É possível que essa identificação não aconteça por uma associação do termo sustentabilidade ainda a dimensão ecológica e uma relação não tão evidente com o sistema de troca de livros. Esse fator também permite compreender que os valores para sustentabilidade passam a estar naturalizados para o consumidor no sistema colaborativo.

Finalmente, o artigo considera a relevância da apropriação das características do processo de difusão dos valores da sustentabilidade nestes contextos para que projetem sistemas de redistribuição de objetos e contribuam para o desenvolvimento de uma cultura sustentável.

\section{REFERÊNCIAS}

ALCOTT, Blake. The sufficiency strategy: Would rich-world frugality lower environmental impact? Ecological Economics. Fev. 2008. v. 64, 4. ed., p. 770-786.

AKATU. Diálogos Akatu. Consumidor, o poder da consciência. São Paulo: Instituto Akatu, 2002.

BAUDRILLARD, J. A sociedade de consumo. Rio de Janeiro: Elfos, 1995.

BELK, R. Sharing. Journal of Consumer Research. V.36, 2010.

BOTSMAN, R. ROGERS, R. O que é meu é seu: como o consumo colaborativo vai mudar o nosso mundo. Porto Alegre: Bookman, 2011.

COMISSÃO MUNDIAL SOBRE MEIO AMBIENTE E DESENVOLVIMENTO. Nosso futuro comum. Rio de Janeiro: Editora da Fundação Getúlio Vargas, 1991.

CONFERÊNCIA DAS NAÇÕES UNIDAS SOBRE O MEIO AMBIENTE E O DESENVOLVIMENTO - ECO 92/RIO 92. Rio de Janeiro, 1992. Agenda 21 Global. Capítulo 4: Mudança dos padrões de consumo. Disponível em http://www. mma.gov.br/estruturas/agenda21/_arquivos/cap04.pdf. Acesso em 29 de janeiro de 2016.

COVA, B. COVA, V. Tribal aspects of postmodern consumption research: the case of French in-line roller skaters. Journal of Consumer Behavior. V.1, 67-76, 2001. 
DOUGLAS, M. ISHERWOOD, B. 0 mundo dos bens. Rio de Janeiro: UFRJ, 2006.

FEATHERSTONE, M. Cultura de consumo e pós-modernismo. São Paulo: Studio Nobel, 1995.

LIPOVETSKY, G. A felicidade paradoxal: ensaio sobre a sociedade do hiperconsumo. São Paulo: Companhia das letras, 2007.

KRUCKEN, Lia. TRUSEN, Cristoph. A comunicação da sustentabilidade de produtos e serviços. In: MORAES, Dijon de. KRUCKEN, Lia. (Org.) Cadernos de estudos avançados em Design: Sustentabilidade I. Barbacena: Editora da Universidade do Estado de Minas Gerais, v.a, 2009. Disponível em http://www.tcdesign.uemg.br/pdf/ Sustentabilidade_I.pdf

MANZINI, Ezio. VEZZOLI, Carlo. O desenvolvimento de produtos sustentáveis. $1^{a}$ ed. $1^{a}$ reimpressão. São Paulo: Editora da Universidade de São Paulo, 2005.

MCCRACKEN, G. Cultura e consumo. Rio de Janeiro: Mauad, 2003. 